\title{
Pressure-flow loops and instantaneous input impedance in the thoracic aorta: Another way to assess the effect of aortic bypass graft implantation on myocardial, brain, and subdiaphragmatic perfusion
}

\author{
Choukri Mekkaoui, $\mathrm{PhD}^{\mathrm{a}, \mathrm{c}}$ \\ Pierre H. Rolland, $\mathrm{PhD}^{\mathrm{a}}$ \\ Alain Friggi, $\mathrm{PhD}^{\mathrm{a}}$ \\ Monique Rasigni, $\mathrm{PhD}^{\mathrm{c}}$
}

Thierry G. Mesana, MD, PhD ${ }^{a, b}$

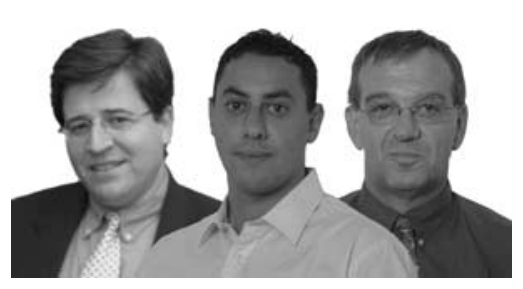

Mesana, Mekkaoui, and Rolland
Background: The serious disturbances in ventriculoarterial coupling after thoracic aorta bypass grafting are addressed through aortic entry impedance in the frequency domain from flow-pressure waves. We designed a method for synthesizing pressure and flow waves to evaluate opposal to aortic flow along the cardiac cycle, addressing myocardial, brain, and visceral tissue perfusions from pressure-flow hysteresis loops and forward-backward aortic entry impedance in the ascending aorta, transverse aortic arch, and distal descending aorta, respectively, before and after extra-anatomic grafting of the descending aorta in the swine.

Methods: Twelve pigs underwent extra-anatomic grafting (woven double-velour prosthesis, 18-mm diameter), bypassing the descending aorta. Periarterial flow and endovascular pressure signals were mathematically synthesized (error minimization) to yield continuous functions of flow, pressure along the cardiac cycle before treatment for mean hemodynamics, pressure-flow hysteresis loops, and aortic entry impedance.

Results: Grafting of the descending aorta overshadowed pressure-flow hysteresis loops in the ascending aorta by shortening maximum pressure delay on maximum flow and diastolic flow reversal. Clamping of the descending aorta substantially restored hemodynamics in the ascending aorta, although the diastolic flow decrease was accelerated. Identical processes developed in the transverse aorta. Subdiaphragmatic descending aortic flow was flattened after grafting and restored, although thickened, after clamping of the descending aorta. Flow wave peak was framed by a diastolic aortic entry impedance peak, which was damped along the transverse aortic arch (aortic entry impedance peak in the ascending aorta, $1700 \pm 102 \mathrm{kN} \cdot \mathrm{s}$ $\cdot \mathrm{m}^{-5}$; aortic entry impedance peak in the descending aorta, $292 \pm 45 \mathrm{kN} \cdot \mathrm{s} \cdot \mathrm{m}^{-5}$; $P<.05)$. After grafting, the aortic entry impedance peak was transferred to early systole (aortic entry impedance peak in the transverse aortic arch, $2104 \pm 94 \mathrm{kN}$. $\mathrm{s} \cdot \mathrm{m}^{-5}$; aortic entry impedance peak in the descending aorta, $450 \pm 75 \mathrm{kN} \cdot \mathrm{s} \cdot \mathrm{m}^{-5}$; $P<.05$ ). Clamping of the descending aorta attenuated the early systolic aortic entry impedance peak (aortic entry impedance peak in the transverse aortic arch, $1269 \pm$ $104 \mathrm{kN} \cdot \mathrm{s} \cdot \mathrm{m}^{-5}$; aortic entry impedance peak in the descending aorta, $491 \pm 75 \mathrm{kN}$ $\left.\cdot \mathrm{s} \cdot \mathrm{m}^{-5} ; P<.05\right)$, although aortic entry impedance in the descending aorta remained higher than before grafting $(P<.05)$. Specifically, the backward flow ascending aorta to coronary trunks generated a backward aortic entry impedance peak $\left(2234 \pm 350 \mathrm{kN} \cdot \mathrm{s} \cdot \mathrm{m}^{-5}\right)$ superimposed onto the forward aortic entry impedance peak with asymptotic boundaries that diminished after grafting and further enlarged after clamping of the descending aorta. 


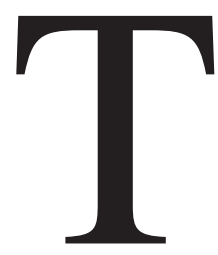

he thoracic aorta is an essential component of flow distribution from the heart to the vital organs. Anatomically, the thoracic aorta represents grossly $80 \%$ of the length of the entire aorta, and physiologically, it is acknowledged that the flow and pressure wave-forming properties are situated in the first half of the conduit. The ascending aorta (AA) morphology, including the unique features of the aortic root, has the utmost importance for myocardial perfusion. The transitional geometry and opposite directions from the vertical AA into the transversal aortic arch (TA) and then into another vertical segment, namely the descending aorta (DA), affects brain perfusion, as well as various subdiaphragmatic vital organs, including the liver and kidneys. Late complications emerge from hemodynamic stirs of poorly compliant graft prosthesis implantation as changes in either (or both) myocardial performances and upstream (coronary and supra-aortic trunks) and downstream (visceral ports) hemodynamics, which depend on optimal ventriculoarterial coupling, optimal thoracic aorta properties, or both to convert cardiac outflow into an appropriate blood flow wave. ${ }^{1,2}$

Pioneering works in the creation of long bypasses from the $\mathrm{AA}^{3}$ or ventricular outflow tract ${ }^{1,2}$ to the abdominal aorta, as well as later studies ${ }^{4-6}$ and simulations, ${ }^{7,8}$ showed that bypasses markedly increased characteristic impedance and lowered aortic total compliance, whereas they slightly changed vascular resistance, which in turn impaired energy transfer in the ventriculoarterial coupling. Pressure- or volume-dependent molecular mechanisms subsequently contribute to the progression of abnormal myocardial energetics and systolic dysfunction characteristics of ventricular failure. ${ }^{9-12}$ Clinical observations documented left ventricular hypertrophy after bypass procedures as a result of increasing aortic input impedance. ${ }^{6,13}$ Conversely, actions on aortic input impedance are of potential therapeutic interest because they improve ventricular function in patients with dilated cardiomyopathy. ${ }^{11,13}$

Myocardial consequences after thoracic aortic surgery usually are identified by calculating input impedance from blood pressure and flow measurements by using frequency domain techniques.9,12,14-16 Impedance then is commonly displayed as amplitude and phase shifts across a frequency spectrum, and finally, the amplitude of the impedance at a given frequency represents the relative resistance to blood flow at that frequency. ${ }^{1-4,6-9,11-16}$ In this way the aortic input impedance offers an appropriate description of the total hydraulic load imposed on the left ventricle because matching heart rate to frequencies that minimize input impedance results in more efficient blood flow by diminishing energy requirements. ${ }^{1,2,12,15-17}$ Nevertheless, even when the frequency analysis provides an appropriate description of the total hydraulic load of the left ventricle, instantaneous measurements of the flow-pressure relationships fail to describe aortic entry impedance ( $\mathrm{Ze}$ ) changes along the cardiac cycle, especially Ze backward and forward variations. From a therapeutic standpoint, we further need to assess the effects that noncompliant conduits, such as bypass Dacron grafts, have on hemodynamics and on upstream and downstream tissue perfusion. In this study we decided to use an extraanatomic bypass graft of the long DA segment, which reproduces clinical situations, such as coarctation or thromboexclusion of the aorta. Then, from data acquisition methods previously developed in our laboratory for hemodynamic investigations of atherosclerosis development and stent implantation in swine, ${ }^{18-20}$ we applied a new mathematic synthesizing method to convert the pressure and flow measurement points into mathematic equations enabling adequate assessment of pressure-flow (P-Q) relationships as $\mathrm{P}-\mathrm{Q}$ hysteresis loops and profiles, all a cardiac cycle along.

\section{Materials and Methods}

Twelve swine (Pietrain/Duroc bred, 10 months old, $73 \pm 3 \mathrm{~kg}$ ) were handled in accordance with the Marseilles School of Medicine's Animal Care and Use Committee, which granted approval of the protocol. As previously described, ${ }^{18-20}$ the swine were anesthetized (intramuscular ketamine, $18 \mathrm{mg} / \mathrm{kg}$, and atropine, 20 $\mu \mathrm{g} / \mathrm{kg}$ ), and ventilated with endotracheal tubing (oxygen-air controlled mixture) and intravenous (ear and vena cava) and intraarterial (superior femoral artery, 6F introducer sheath; BSC) lines for pressure monitoring. Six ECG leads and an $\mathrm{SaO}_{2} /$ plethysmographic tail probe (HP78354C) were placed, and then animals were anesthetized (chloralose/urethane 5:25\%; w/v, $1.25 \mathrm{~mL} / \mathrm{kg}$ ) and perfused with Ringer lactate $\left(15 \mathrm{~mL} \cdot \mathrm{kg}^{-1} \cdot \mathrm{h}^{-2}\right)$ solution. Aseptic techniques were used with prophylactic antibiotics (amoxicillin/ clavulanic acid $1 \mathrm{~g}: 200 \mathrm{mg}, 20 \mathrm{~mL}$, intravenous). A left posterior thoracotomy (fourth to sixth intercostal spaces) was performed before controlling the thoracic aorta at the measurement and grafting sites. Before aortic clamping, anticoagulation (clotting time $>500$ seconds) was performed by means of central administration of heparin (350 IU/kg heparin; Choay) and, to attenuate aortic crossclamping-induced changes in hemodynamics and heart rate, 
the animals received esmolol-chloridrate (Brevibloc, $100 \mathrm{mg} / 10$ $\mathrm{mL}$; Sigma-Tau) as $500 \mu \mathrm{g} \cdot \mathrm{kg}^{-1} \cdot \mathrm{min}^{-1}$ within 1 minute before clamping and $50 \mu \mathrm{g} \cdot \mathrm{kg}^{-1} \cdot \min ^{-1}$ for the next 10 minutes to return arterial pressure and heart rate to basal values; the effects of esmolol disappeared within 15 to 20 minutes. The aortic sites to be investigated (Figure 1) were $2 \mathrm{~cm}$ below the AA pericardial reflexion for the AA, $2 \mathrm{~cm}$ after the left subclavian artery embranchment for the TA, and $2 \mathrm{~cm}$ above the diaphragm for the TA. Side aortic crossclamping for graft implantation was performed in the distal aortic arch and $4 \mathrm{~cm}$ into the distal DA. A woven double-velour vascular graft (Hemashield, Meadox Medicals Inc) extended from the upper DA (between the anterior bronchial arteries and the first posterior intercostal arteries embranchment) to the DA. Measurements of aortic diameter yielded values of 20.2, 18.4 , and $15.4 \mathrm{~mm}$ for the AA, TA and DA, respectively. The vascular graft was $18 \mathrm{~mm}$ in diameter, and length was determined so that the graft paralleled the DA, realizing $45^{\circ}$ aorta-to-graft angles. Animals were killed with $15 \mathrm{~mL}$ of $20 \% \mathrm{KCl}$ administered intravenously.

\section{Hemodynamics}

The methods and devices used for measuring flow and pressurewaveforms were as previously described, ${ }^{18-20}$ with the following adaptative changes. The thoracic aorta was tethered in 3 sites for permanent insertion of perivascular flow probes. Flow measurements were carried out by using a T206S flowmeter (Transonic Systems Inc) with appropriate 16- to $24-\mathrm{mm} \mathrm{SB} / \mathrm{RB}$ perivascular flow probes. Intravascular pressure measurements were performed with a 2F Mikro-Tip catheter pressure transducer (SPR-249/Millar Instruments Inc) advanced under fluoroscopy to the precise aortic positions by using a guiding catheter (Britetip/MP/A1/6F, Cordis). The guiding catheter was withdrawn to the abdominal aorta during simultaneous P-Q measurements at the same site. Hemodynamic measurements (chronologically: AA, TA, and DA) were performed before and after grafting and then after DA clamping; in each new situation, a 20-minute period of time elapsed under continuous pressure and flow monitoring to enable hemodynamic equilibration. It was finally checked that hemodynamics returned to the previous level after removal of DA clamping. Analog signals were recorded and digitized (ATMIO-16X, 16 bits ADC, 500-Hz sampling frequency, National Instruments). Data were recorded for 50 cardiac cycles and treated by using the custom-designed data-capturing window in Labview software (National Instruments).

\section{Mathematic Analysis and Synthesis of Flow and Pressure Waveforms}

The study aimed at determining mean hemodynamics, P-Q relationships as P-Q hysteresis loops, and profile from mathematic synthesis of P-Q waves along a cardiac cycle. Cycle-to-cycle wave variability was overcome by generating a steady-state cycle (256 points) from time-averaged P-Q cardiac cycles calculated by using linear interpolation (mean period): $T=\frac{1}{N_{c} f} \sum_{j=1}^{N_{c}} N_{j}$, where $\mathrm{N}_{\mathrm{j}}$ is defined as the number of points within each cardiac cycle, $\mathrm{N}_{c}$ is defined as the number of cycles, and $\mathrm{f}$ is defined as the sampling frequency. ${ }^{19}$

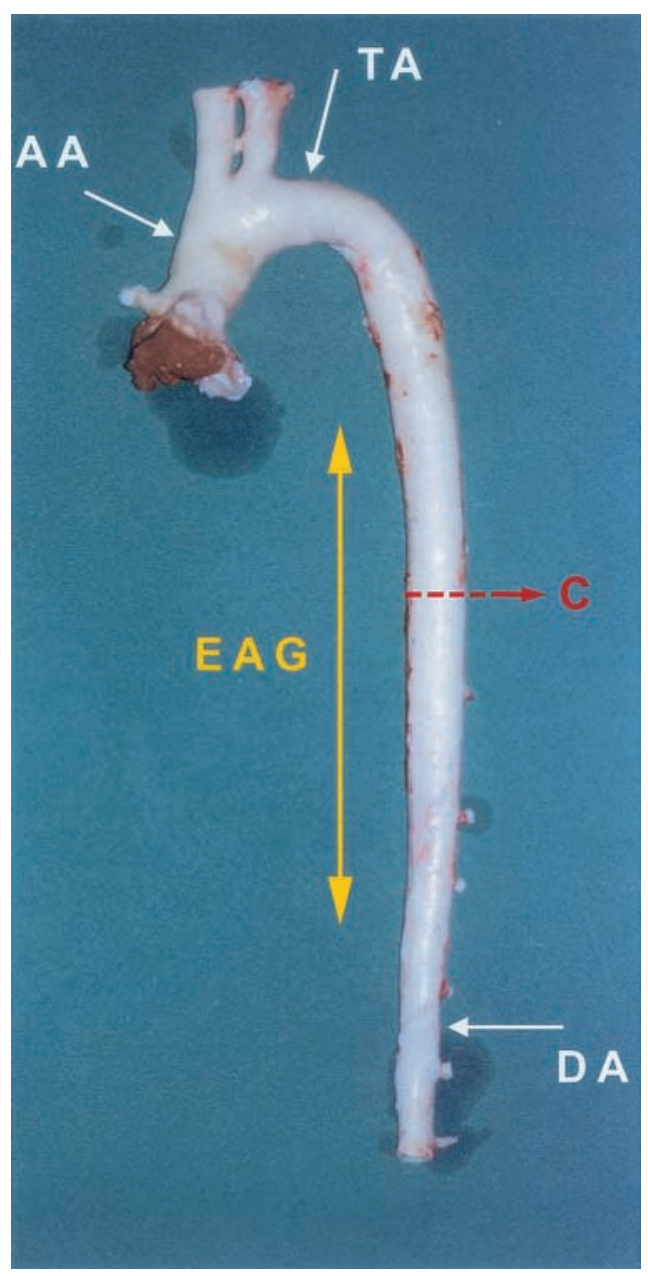

Figure 1. The 3 sites for hemodynamic measurement were the $A A$, the TA, and the DA. The extra-anatomic bypass graft (EAG; double-headed arrow) was proximally inserted between the bronchial arteries and the first intercostal arteries embranchment. The native DA after grafting finally was clamped (C).

The discrete pressure and flow signals were the resulting waves carrying energy and quantity of movement along the thoracic aorta. The following schedule was followed to obtain the pressure and flow analytic functions. First, complex pressure and flow waveforms were fractionated into successive segments of curves separated by 2 opposite extreme points, which were scaled (Figure 2 and Appendix 1). A mathematic modeling of the segment has been developed that applied to each segment after scaling of the 2 extreme points to measured values, offsetting in 2-dimensional coordinate axis, and settling into the increasing or decreasing nature of the waveform segment (Appendix 2). The initial waveform was synthesized by summing individual segments and fitting the curve to the original pulse wave to obtain the error, which was treated in the same manner. The final function was the sum of the serial functions. The model applied to both pressure and flow measured waves. The quadratic error normalized to the original waveforms was found to be very low, irrespective of the experimental conditions (Figure 3 and Appendix 3). 

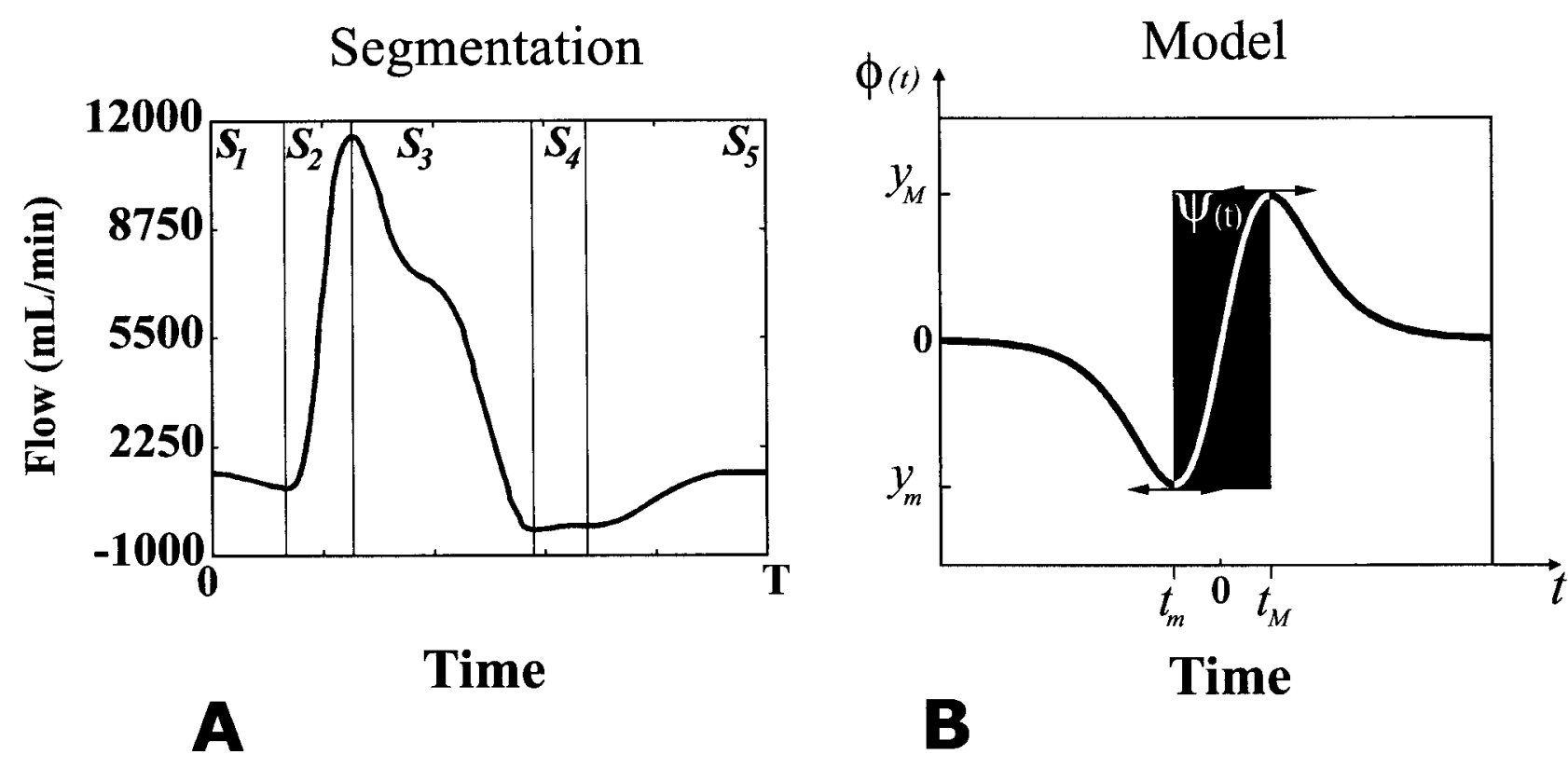

Time

Figure 2. The first 2 steps in mathematic synthesizing of the measured flow waveform in the native AA. A, The flow wave was fractioned into successive segments of curves separated by 2 opposite extreme points according to an algorithm described in Appendix 1. B, Each elementary segment of curve, after scaling the 2 extreme points to measured values, was synthesized into the mathematic function and further considered as part of the second derivative of a sigmoidal function.

Calculation of Mean Hemodynamics, P-Q Hysteresis Loops, and Entry Impedance

From their respective P-Q functions, we calculated basic hemodynamics as a list of scalar parameters, P-Q hysteresis loops as a system of parametric functions, and instantaneous $\mathrm{Ze}$ as the ratio of pressure and flow functions (Appendix 4).

\section{Statistical Analysis}

Data treatment and statistical analyses were performed by using Systat 9.0 software (SASS Inc). Results are given as mean \pm SD. Statistical analysis was performed with the Kruskal-Wallis test (ie, nonparametric analog of 1-way analysis of variance), which was reduced to the Mann-Whitney test (ie, nonparametric analog of 2-sample $t$ test) when there were 2 groups.

\section{Results}

Data on mean hemodynamics in the thoracic aorta are shown in Table 1. In the native aorta pulsatile cardiac outflow decreased as diastolic flow increased with position along the overall thoracic aorta, whereas systolic and pulse flows decreased and mean $\overline{\mathrm{Ze}}(\overline{\mathrm{Ze}})$ increased from AA to TA only. Grafting DA decreased diastolic pressure and mean and diastolic flow and increased peripheral resistance and $\overline{\mathrm{Z} e}$ while decreasing the flow in the AA and DA, although not immediately upstream of the graft in the TA. The results indicate that extra-anatomic bypass grafting diminished cardiac outflow while preserving flow input in the TA to the detriment of both coronary and brain flow and decreased flow pulsatility downstream of the graft in the DA. Driving flow solely into the graft by clamping the DA kept mean flow constant while decreasing diastolic and mean blood pressure subsequently and increased diastolic flow with the accompanying decreases in systolic flow and change in flow in the AA. The stiff graft offered additional resistance to blood flow. As in clamped conditions, peripheral resistance and $\overline{\mathrm{Z} e}$ increased in the thoracic aorta. Grafting the DA therefore partially restored the upstream coronary and brain perfusion but failed to restore flow pulsatility downstream in the DA.

The population-averaged P-Q hysteresis loops in the 3 different situations (Figure 4) describe how the measured changes in hemodynamics proceeded along the cardiac cycle. In the native AA systolic flow increased early with an abrupt P-Q slope before the peak and plateaued at maximum flow, whereas pressure had still not reached its maximum value. This indicates that the walls of the AA contributed to flow by expanding rapidly and remaining widely open during systole. The flow diastolic phase elicited a substantial reversal episode related to coronary diastolic filling and (with much lower extent) valvular reflux.

After bypass implantation, the systolic flow increase remained similar in shape but substantially decreased in magnitude, and diastolic flow no longer reversed at middi- 

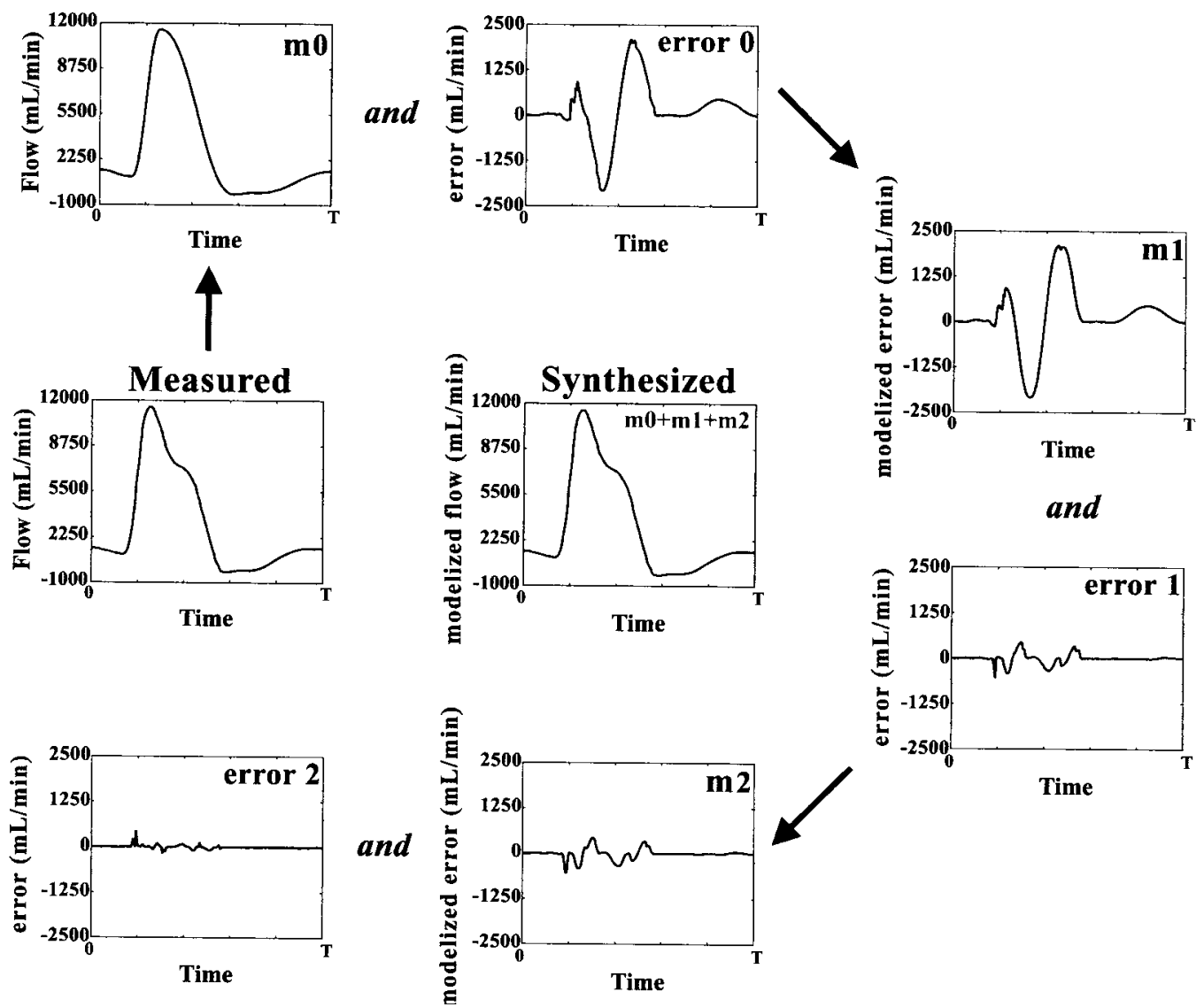

Figure 3. The measured flow waveform was synthesized by summing the individual successive segments and fitting the curve to the original pulse wave to obtain the first model $\mathrm{m} 0$ and error $\mathbf{0}$. Error $\mathbf{0}$ was iteratively treated in the same manner to give $\mathrm{m} 1$ and error 1 and $\mathrm{m} 2$ and error 2 , subsequently. The synthesized function finally was the sum of serial functions. The model applied to both pressure and flow measured waves, with a quadratic error normalized to original waveforms ranging from $10^{-7}$ to $10^{-8}$, irrespective of the experimental conditions.

astole. Clamping the DA forced the pressure and flow systolic waves to concomitantly peak in the AA because diastolic flow reversal occurred when diastolic pressure was still increased. Coronary flow-driving forces therefor moved from early to last diastole. This graphic view is supported by calculated flow waveform surfaces in the mean cardiac cycles: the forward and backward blood volumes decreased from $36.95 \pm 1.23$ and $0.93 \pm 0.09 \mathrm{~mL} /$ cycle in the AA before grafting to $19.61 \pm 1.02$ and $0.18 \pm$ $0.06 \mathrm{~mL} /$ cycle in the AA after grafting $(P<.05)$, respectively. After clamping, forward and backward blood volume again increased to $23.69 \pm 1.05$ and $1.03 \pm 0.09 \mathrm{~mL} /$ cycle in the AA, respectively $(P<.05)$.

In the TA P-Q loops exhibited similarities to AA loops: maximum flow preceded maximum pressure, and there existed diastolic backward flow to the supra-aortic trunk, although to a lower extent than in the AA. The processes also were furthered in the grafted TA. In contrast, they were restored after aortic clamping, although they were flattened compared with those in the native situation. The blood volume diminished slightly from $21.94 \pm 1.87 \mathrm{~mL} /$ cycle in the TA to $16.56 \pm 1.43 \mathrm{~mL} /$ cycle in the $\mathrm{DA}$ and further decreased to $9.78 \pm 0.98 \mathrm{~mL} / \mathrm{cycle}$ after clamping $(P<$ $.05)$.

In the DA hysteresis loops contrasted with those in the AA and TA, with the former presenting the stiff characteristics of the viscoelastic abdominal aorta. (Maximum pressure was reached as systolic flow was still increasing to maximum flow, and the decreasing diastolic flow rate was lower than decreasing pressure rate.) After bypassing the DA, the P-Q loop was drastically flattened downstream of the graft. Clamping the DA substantially restored the flow profile, although the diastolic flow wave decrease was accelerated. In parallel blood volume substantially decreased from $22.72 \pm 1.87 \mathrm{~mL} /$ cycle in the DA to $12.29 \pm 1.21$ $\mathrm{mL} /$ cycle in the grafted DA $(P<.05)$ and remained identical $(10.69 \pm 1.01 \mathrm{~mL} / \mathrm{cycle})$ after clamping.

The population-averaged entry impedance profile (Fig- 
TABLE 1. Basic hemodynamics in the porcine thoracic aorta

\begin{tabular}{lccccc}
\hline & $\begin{array}{c}\text { Systolic pressure } \\
(\mathbf{m m} \mathbf{~ H g})\end{array}$ & $\begin{array}{c}\text { Diastolic pressure } \\
(\mathbf{m m ~ H g})\end{array}$ & $\begin{array}{c}\text { Change in pressure } \\
(\mathbf{m m} \mathbf{~ H g})\end{array}$ & $\begin{array}{c}\text { Mean pressure } \\
(\mathbf{m m} \mathbf{H g})\end{array}$ & $\begin{array}{c}\text { Systolic flow } \\
(\mathbf{m L} / \mathbf{m i n})\end{array}$ \\
\hline N AA & $148 \pm 9$ & $117 \pm 8$ & $30.3 \pm 4.2$ & $133 \pm 9$ & $10,977 \pm 2095^{*} \dagger$ \\
N TA & $154 \pm 10$ & $126 \pm 9$ & $27.8 \pm 5.1$ & $142 \pm 10$ & $6095 \pm 1439^{*} \dagger$ \\
N DA & $157 \pm 8$ & $124 \pm 9$ & $33.6 \pm 6.0$ & $140 \pm 10$ & $4856 \pm 1143^{*} \ddagger$ \\
EAG AA & $146 \pm 10$ & $111 \pm 9$ & $35.4 \pm 4.7$ & $128 \pm 7$ & $7496 \pm 1474^{*} \S$ \\
EAG TA & $143 \pm 8$ & $109 \pm 7 \S$ & $34.2 \pm 3.8$ & $126 \pm 7 \S$ & $5108 \pm 1107^{*}$ \\
EAG DA & $143 \pm 7$ & $106 \pm 6 \S$ & $37.5 \pm 6.2$ & $121 \pm 6 \S$ & $2754 \pm 555^{*} \S$ \\
C AA & $145 \pm 8$ & $112 \pm 7$ & $32.8 \pm 4.7$ & $128 \pm 6 \S$ & $5838 \pm 876 \dagger \S$ \\
C TA & $135 \pm 8$ & $95 \pm 6 \S$ & $40.3 \pm 4.1$ & $111 \pm 6 \S$ & $2379 \pm 429 \dagger \S$ \\
C DA & $146 \pm 8$ & $113 \pm 7$ & $33.2 \pm 5$ & $129 \pm 6 \S$ & $2361 \pm 562 \S$ \\
\hline
\end{tabular}

Values are expressed as means \pm SEM. $N$, Native; EAG, extra-anatomic graft; $C$, clamped mid-DTA; HPR, mean peripheral resistance; $Z e$, mean entry impedance.

${ }^{*} P<.005$, Kruskall-Wallis one-way analysis of variance, grouping variable was site

$\dagger P<.05$ AA versus TA and $¥ P<.05$ TA versus DA, post-hoc tests; categoric value was site (2-sided probability).

$\S P<.05$ native versus EAG or $C$, Mann-Whitney $U$ test (2-sided probability).

ure 5) before grafting shows that $\mathrm{P}-\mathrm{Q}$ wave peaks were framed in all thoracic aortas by increased $\overline{\mathrm{Z} e}$ episode. $\overline{\mathrm{Z} e}$ peak lengthened most during diastole, cropping up as $\mathrm{P}-\mathrm{Q}$ systolic peaks returned to minimal values. As the distance from the heart increases, $\overline{\mathrm{Ze}}$ peak and $\overline{\mathrm{Ze}}$ plateau decreased from $1700 \pm 102$ and $459 \pm 34 \mathrm{kN} \cdot \mathrm{s} \cdot \mathrm{m}^{-5}$ in the TA to $292 \pm 45$ and $231 \pm 51 \mathrm{kN} \cdot \mathrm{s} \cdot \mathrm{m}^{-5}$ in the DA, respectively, whereas the valley under P-Q peaks increased from $56 \pm 12 \mathrm{kN} \cdot \mathrm{s} \cdot \mathrm{m}^{-5}$ in the TA to $71 \pm 18 \mathrm{kN} \cdot \mathrm{s} \cdot \mathrm{m}^{-5}$ in the DA $(P<.05)$. Figure 5 also shows that additional impedance events having asymptotic boundaries superimposed onto the profile but only in the AA. They were mathematically attributable to changes in flow slopes and directions. Specifically, the early diastolic flow was decreasing (ie, it had a negative slope) but was still forward in direction before turning to backward flow (ie, as crossing zero flow value). Thereafter (the time of mitral valve opening), the backward flow lowered (ie, returned to a positive slope), before turning into a forward flow as crossing zero flow value (Figure 5, insert). The forward $\overline{\mathrm{Ze}}$ peak correlated the changes in the flow slope, whereas the superimposed backward peak dropped between the 2 flow zero value, crossing over with asymptotic boundaries. Therefore the backward flow fulfilling the coronary trunks had its own backward peak $\left(2234 \pm 350 \mathrm{kN} \cdot \mathrm{s} \cdot \mathrm{m}^{-5}\right)$.

Graft implantation induced a presystolic new $\overline{Z e}$ peak and reduced the previous diastolic $\overline{\mathrm{Ze}}$ peak in length in the AA and both in length and magnitude in the TA $(P<.05)$. The diastolic $\overline{Z e}$ peak was changed into a sole plateau in the DA (Figure 6). The diastolic $\overline{Z e}$ peak decreased from $948 \pm$ $72 \mathrm{kN} \cdot \mathrm{s} \cdot \mathrm{m}^{-5}$ in the TA to $439 \pm 65 \mathrm{kN} \cdot \mathrm{s} \cdot \mathrm{m}^{-5}$ in the $\mathrm{DA}$. The emerging presystolic $\overline{\mathrm{Ze}}$ peak decreased from $2104 \pm 94 \mathrm{kN} \cdot \mathrm{s} \cdot \mathrm{m}^{-5}$ in the TA to $450 \pm 75 \mathrm{kN} \cdot \mathrm{s} \cdot \mathrm{m}^{-5}$ in the DA downstream of the graft. In contrast, the valley under the P-Q peaks increased from $62 \pm 12 \mathrm{kN} \cdot \mathrm{s} \cdot \mathrm{m}^{-5}$ in the TA to $109 \pm 18 \mathrm{kN} \cdot \mathrm{s} \cdot \mathrm{m}^{-5}$ in the DA $(P<.05)$.
Further clamping the DA decreased the diastolic $\overline{\mathrm{Ze}}$ peak in the AA from a forward profile toward a backward profile, thereby reducing the systolic peak to its asymptotic boundaries and enlarging the diastolic peak by amplifying the diastolic flow rates of decrease (Figure 7). The diastolic $\overline{\mathrm{Ze}}$ peak was identical in the TA and DA $(669 \pm 52$ and $603 \pm$ $65 \mathrm{kN} \cdot \mathrm{s} \cdot \mathrm{m}^{-5}$, respectively, otherwise significantly higher than their values in the native DA, $P<.05$ ). The presystolic peak decreased from $1269 \pm 104 \mathrm{kN} \cdot \mathrm{s} \cdot \mathrm{m}^{-5}$ in the TA to $491 \pm 75 \mathrm{kN} \cdot \mathrm{s} \cdot \mathrm{m}^{-5}$ in the DA, whereas the valley under the P-Q peaks increased from $127 \pm 12 \mathrm{kN} \cdot \mathrm{s} \cdot \mathrm{m}^{-5}$ in the AA to $132 \pm 38 \mathrm{kN} \cdot \mathrm{s} \cdot \mathrm{m}^{-5}$ in the DA $(P<.05)$. Clamping the DA therefore again partly increased the systolic forward flow and amplified the backward flow during diastole, which subsequently favored the coronary flow drive.

\section{Discussion}

\section{The New Mathematic Model Enables Analysis of P-Q} Waves and Instantaneous $\overline{\mathrm{Ze}}$

The mathematic synthesis to convert P-Q waves from finite measurement points (acquired at the sampling frequency with respect to the Shannon theorem) into lowerror $\left(<10^{-7}\right)$ continuous functions is the physical preliminary requirement to address the $\mathrm{P} / \mathrm{Q}$ ratio as instantaneous $\overline{\mathrm{Ze}}$. Because the measured $\mathrm{P}-\mathrm{Q}$ propagating waves carry energy along the thoracic aorta, $\overline{\mathrm{Ze}}$ is characteristic of the whole arterial bed downstream to the point of measurement in the direction of blood flow. The energy receiver status enables description of the in-place opposition to propagating waves, with the physiologic consequences of fulfilling the coronary, brain, and visceral ports in the forward and backward flow directions. In these settings there is no energetic conflict or opposition between flow (a kinematic energy) and pressure (a potential dynamic energy) when kinetic energy precedes the dynamic potential energy because the latter is con- 


\begin{tabular}{|c|c|c|c|c|}
\hline $\begin{array}{l}\text { Diastolic flow } \\
\text { (mL/min) }\end{array}$ & $\begin{array}{l}\text { Change in flow } \\
(\mathrm{mL} / \mathrm{min})\end{array}$ & $\begin{array}{c}\text { Mean flow } \\
\text { (mL/min) }\end{array}$ & $\begin{array}{c}\mathrm{HPR} \\
\left(\mathrm{mm} \mathrm{Hg} \cdot \mathrm{min}^{-1} \cdot \mathrm{mL}\right)\end{array}$ & $\begin{array}{c}\overline{\mathrm{Ze}} \\
\left(\mathrm{mm} \mathrm{Hg} \cdot \mathrm{min}^{-1} \cdot \mathrm{mL}\right)\end{array}$ \\
\hline$-172.9 \pm-80.2^{*} \dagger$ & $11,150 \pm 1983^{*} \dagger$ & $3103 \pm 746^{*} \dagger$ & $0.0432 \pm 0.008 * \dagger$ & $0.0027 \pm 0.0012^{*} \dagger$ \\
\hline $182.7 \pm 75.8^{*} \dagger$ & $5912 \pm 1169^{*} \dagger$ & $2193 \pm 364^{*}+$ & $0.0648 \pm 0.009 * \dagger$ & $0.0047 \pm 0.0011^{*} \dagger$ \\
\hline $1027 \pm 466^{*} \ddagger$ & $3828 \pm 877^{*} \ddagger$ & $2271 \pm 379^{*}$ & $0.0616 \pm 0.005^{*}$ & $0.0086 \pm 0.0024^{*}$ \\
\hline$-60.9 \pm 23.1 * \S$ & $7557 \pm 1566^{*}+\S$ & $1705 \pm 311^{*} \S$ & $0.0755 \pm 0.0081 \S$ & $0.0047 \pm 0.0009 * \S$ \\
\hline $115.4 \pm 67.4^{*}$ & $4993 \pm 1017^{*} \dagger$ & $1656 \pm 319^{*}$ & $0.0764 \pm 0.0076$ & $0.0069 \pm 0.0008^{*}$ \\
\hline $525.4 \pm 112.3^{*} \S$ & $2229 \pm 513^{*} \pm \S$ & $1229 \pm 265^{*} \S$ & $0.0992 \pm 0.0086 \S$ & $0.0168 \pm 0.0032 * \S$ \\
\hline$-368 \pm 102^{*} \S$ & $6166 \pm 1139 \S$ & $1113 \pm 393 \S$ & $0.1155 \pm 0.035 \S$ & $0.0053 \pm 0.0004 \S$ \\
\hline $367 \pm 101 * \S$ & $2012 \pm 459 \S$ & $1027 \pm 279 \S$ & $0.1267 \pm 0.018 \S$ & $0.0210 \pm 0.0012 \S$ \\
\hline $461 \pm 119 * \S$ & $1999 \pm 397 \S$ & $1068 \pm 378 \S$ & $0.1215 \pm 0.023 \S$ & $0.0166 \pm 0.0111 \S$ \\
\hline
\end{tabular}

vertible into the former if required. ${ }^{4,16}$ Because P-Q hysteresis loops revealed that the AA permits the maximum amount of blood to flow in advance to pressure, whereas pressure and flow peaks are coalescent below in the TA, and because both the diastolic peak and plateau decreased along the thoracic aorta, hemodynamics in the AA and, to a lesser extent, in the TA preserve a kinematic and then dynamic potential organization for the flow energetics during the cardiac cycle, which is an optimal design for heart and brain perfusion. Also, gathering both energy types in the DA optimally shaped the flow wave to the visceral port. ${ }^{1,4}$ The thoracic aorta therefore has the intrinsic hemodynamic properties to ensure that an assistance to flow drives to the branched tissue perfusion.

\section{Consequences of Extra-anatomic Grafting}

The results show that the acknowledged opposition to blood flow exerted by the extra-anatomic bypass in the $\mathrm{DA}^{1-9}$ was in fact accounted for by a presystolic $\bar{Z} e$ peak upstream of the graft and was cumulative with doubling in magnitude of the diastolic $\overline{Z e}$ further downstream of the graft. The physiologic architecture of the diastolic flow assistance to upstream embranchments was disadvantaged by erasing the early diastolic phase $\overline{\mathrm{Ze}}$ peak. Forcing the flow to the graft conduit markedly restored the quality of blood flow in the grafted TA by reducing the early systolic peak and enlarging the diastolic $\overline{\mathrm{Ze}}$ peak and by shifting down the diastolic peak from a forward profile toward a backward profile concomitantly. Finally, the results emphasized that the aortic flow to the downstream visceral port was disadvantaged by DA bypassing; either the native aorta was clamped or it was not.

The striking observation in the present study is that the well-known early cardiac compensatory responses to grafting a long stiff conduit from the cardiac outflow tract to the abdominal aorta ${ }^{1-3,5,6,11-13}$ were not detectable, whereas to the contrary, lowering cardiac output develops after graft-induced relief in AA and TA flows. Distal to the heart (ie, after the major branching of the coronary and supra-aortic trunks), such an opposition to blood flow generated a (moderate) well-known jet stream-like process at the entrance of the prosthesis-DA bifurcation. ${ }^{21}$ The process partly emptied the AA and TA to pertain blood flow immediately upstream the graft but to the detriment of blood flow drives to coronary and supraaortic trunks. Clamping the DA returned flow profiles to basic features by restoring diastolic fluxes to coronary and brain territories through different processes than increasing loading in thoracic aortic segments I and II. The responses again were achieved without generating the previously established cardiac contractile compensatory responses. . $^{-3,5,6,11-13}$ However, these studies also demonstrated that the myocardial response to implanting a stiff conduit in the aorta was found to be more pronounced when the graft was implanted directly onto the aortic root than when implanted downstream in the AA. Our results therefore strongly support the view that implanting the graft in the DA was not capable of inducing the appropriate signals driving the myocardial energetic response. As speculative attempts to explain the absence of compensatory cardiac effects, it should be noted that grafting the DA distally from the heart enables the aortic root and AA to play their forming actions on the blood flow wave, which is obviously not the case when grafting the aortic root directly. Alternately, it is also noticeable that with regard to peripheral resistance and $\overline{\mathrm{Z} e}$ mean values, TA hemodynamically was less affected than the AA and DA were by DA grafting, obviously because of TA localization immediately upstream of the graft. It is 

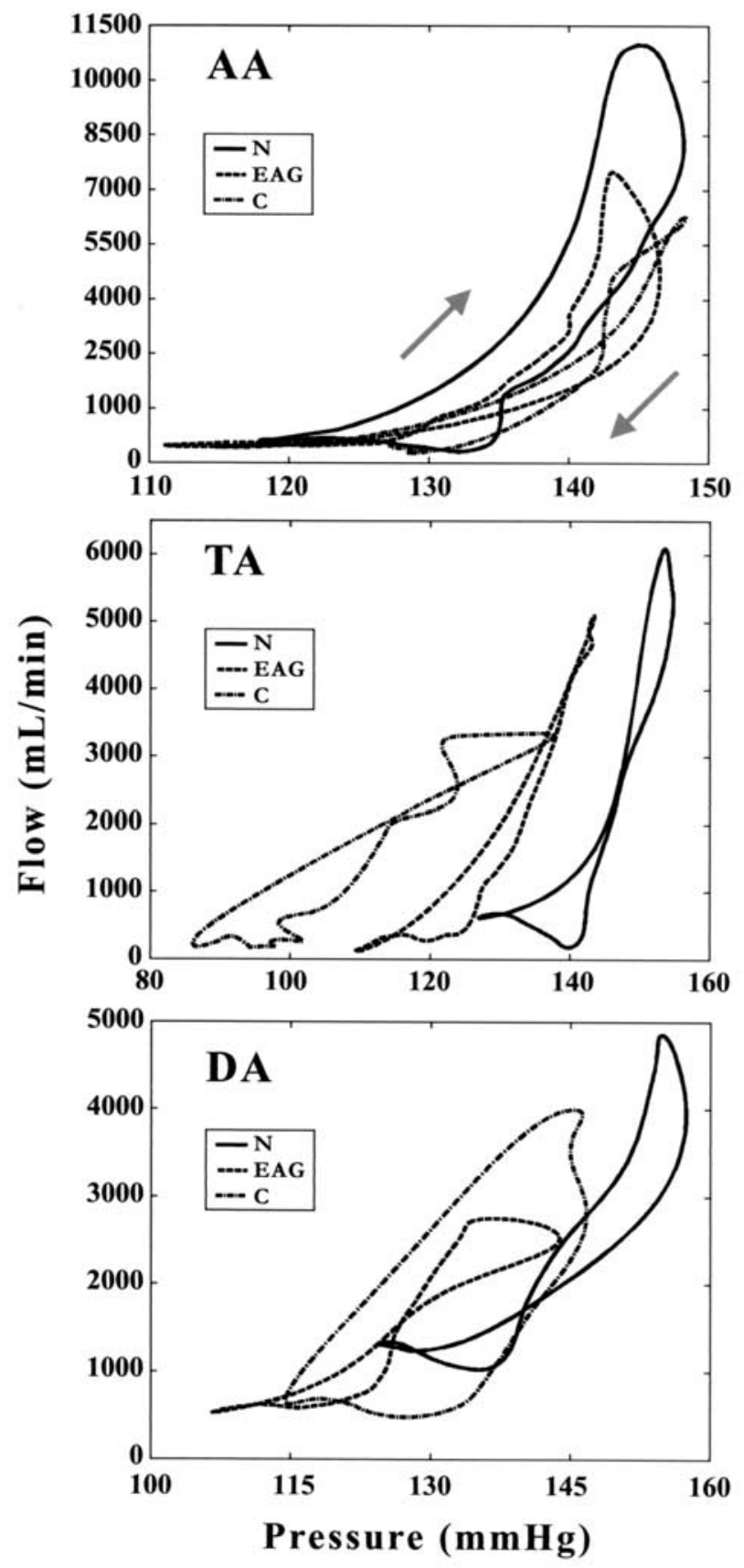

Figure 4. Synthesized pressure and flow waves were plotted as parametric equations for $\mathbf{P}-\mathbf{Q}$ relationships to give the hysteresis loops in the $A A$, the TA, and the DA in the native $(N)$ and grafted DA, before (EAG) and after (C) clamping of the DA. Arrows indicate the direction of loops.

therefore conceivable that unidentified sensors for the cardiac compensatory effects are located at this site. Such hypotheses deserve further experimental investigations of the aortic blood flow under pharmacologic and mechanical manipulation of the AA and TA.
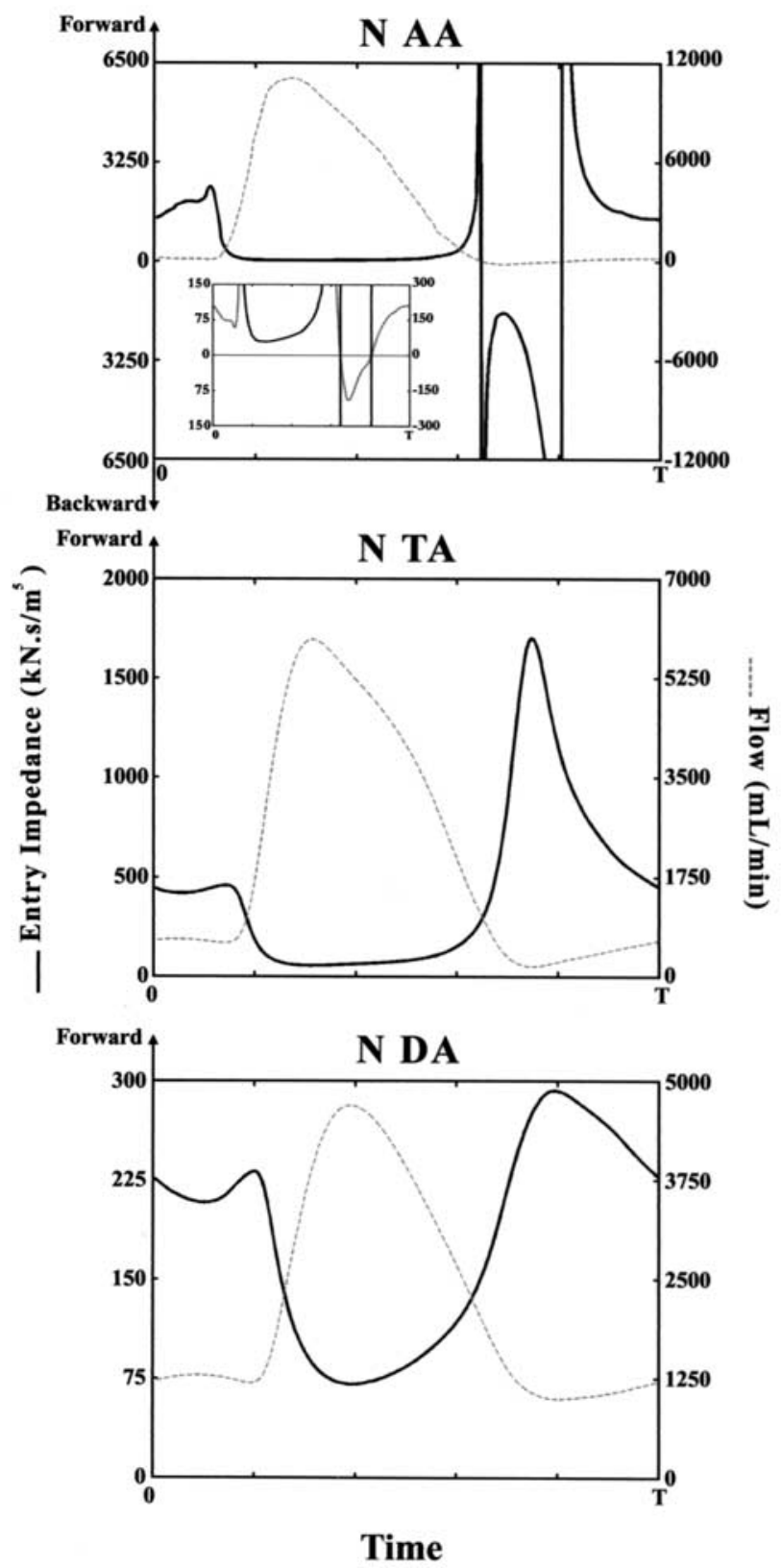

Figure 5. The entry impedance, as calculated from pressure and flow functions along a mean cardiac cycle, is plotted in conjunction with measured flow waves in the native $A A(N A A)$, the native TA (N TA), and the native DA (N DA). Changes in the vicinity of zero values are magnified (insert) in the native $A A$ to highlight the forward-backward changes in impedance and their flow counterparts.

Possible Extension From Hemodynamics to Biomechanics: Clinics and Therapeutics

Potential extensions of the present results into vascular biomechanical changes in the $\overline{\mathrm{Ze}}$ profile are limited by the putative relationships lying between $\mathrm{P}-\mathrm{Q}$ waves and biome- 

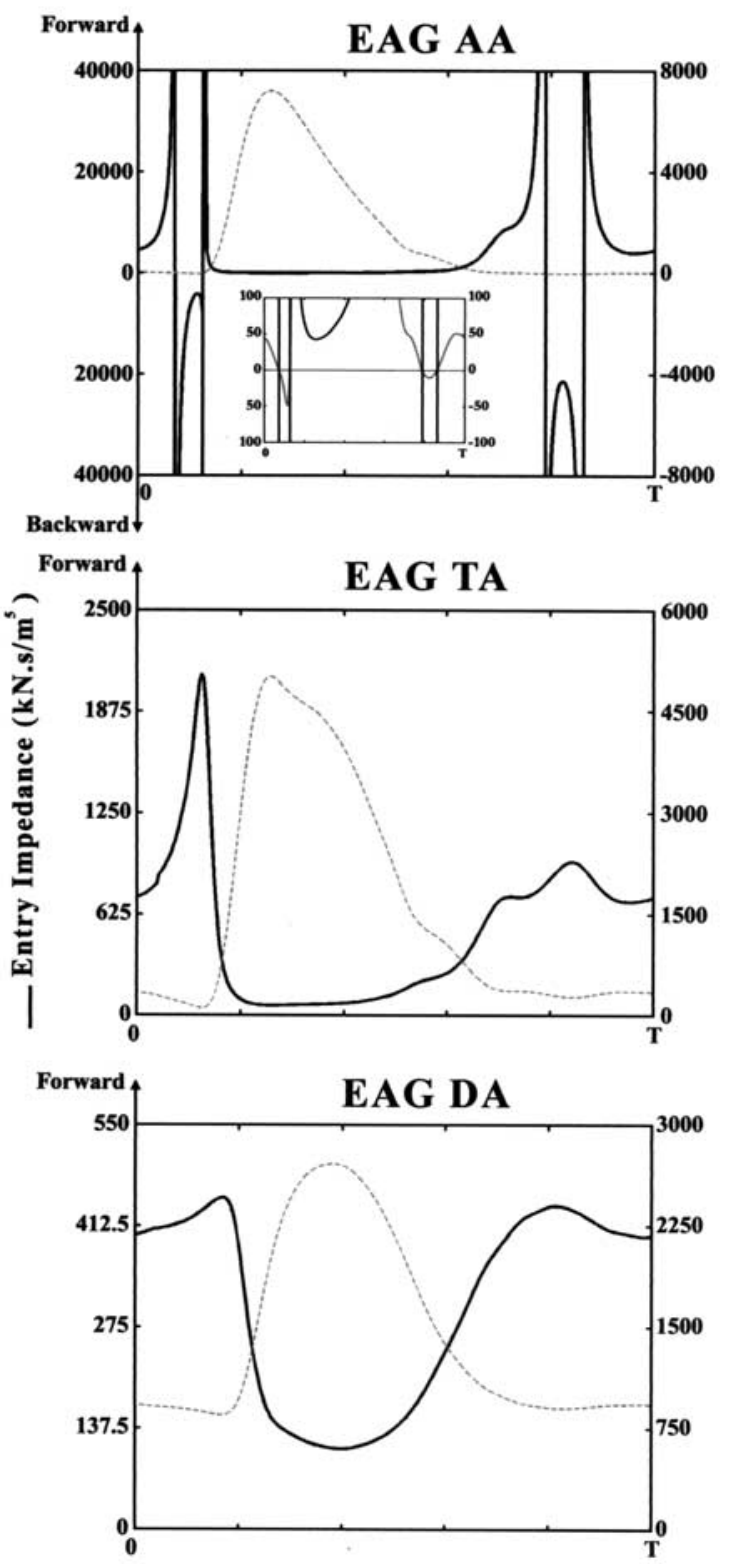

Time

Figure 6. The entry impedance, as calculated from pressure and flow functions along a mean cardiac cycle, is plotted in conjunction with measured flow waves in the extra-anatomically grafted AA (EAG AA), the extra-anatomically grafted TA (EAG TA), and the extra-anatomically grafted DA (EAG DA). Changes in the vicinity of zero values are magnified (insert) in the extra-anatomically grafted AA to highlight the forward-backward changes in impedance and their flow counterparts.

chanical properties of the thoracic aorta. Because it has recently been stressed that inferring mechanical properties of an arterial system from measured pressure and flow, now referred to as the hemodynamic inverse problem, is ques-
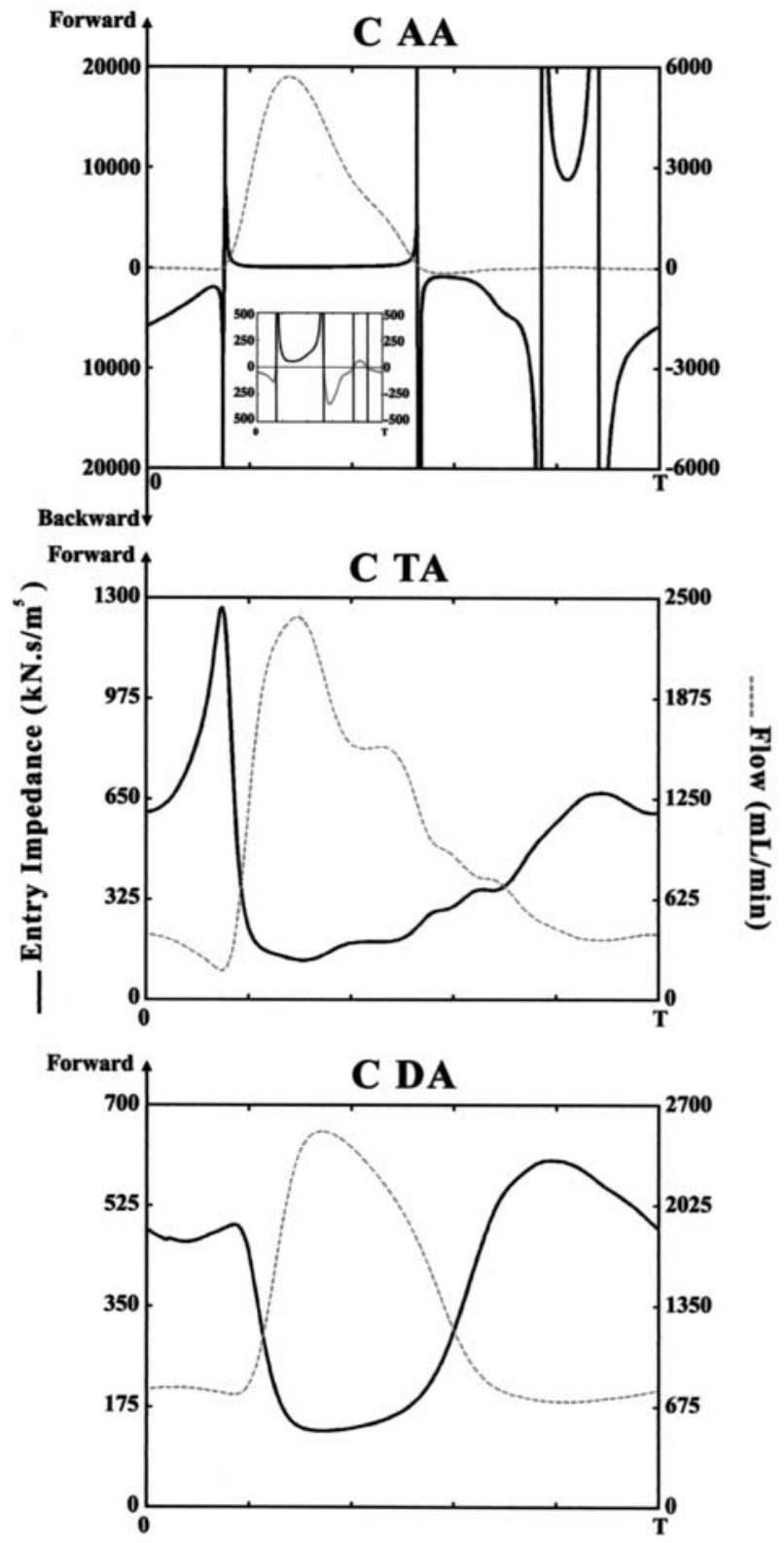

Time

Figure 7. The entry impedance, as calculated from pressure and flow functions along a mean cardiac cycle, is plotted in conjunction with measured flow waves after clamping of the native DA in the extra-anatomically grafted $A A(C A A)$, the extra-anatomically grafted TA (C TA), and the extra-anatomically grafted DA (C DA). Changes in the vicinity of zero values are magnified (insert) in the extra-anatomically grafted AA to highlight the forward-backward changes in impedance and their flow counterparts.

tionable because there exists an infinite number of solutions of different arterial systems describing a measured pressureflow pair. ${ }^{16}$ Studying the aortic solid mechanics of the thoracic aorta through local measurements of diameters and 
pressure is required to determine from where the changes in hemodynamics originated.

Although clinical implications and therapeutic perspectives for the results remain in the speculative domain until prospective investigations are carried out, the present results provide potential mechanisms for some well-known acute or late complications to aortic surgery, as well as cardiac consequences. Specifically, it remains to be established to what extent changes in aortic hemodynamics and subsequent brain perfusion contribute to the neurologic outcome after thoracic aortic surgery. ${ }^{23,24}$ Changes in TA hemodynamics could participate in embolic complications by loosening atheromatous plaques, as well as contributing to temporary neurologic dysfunction, long-term deficits in cognitive functions, ${ }^{14,22,23}$ or spinal cord ischemia, ${ }^{24}$ depending on compensatory adaptative changes by the brain or intercostal arteries.

Alternately, long-term follow-up with sophisticated imaging methods after surgical intervention (including redo operations) of coarctation of the aorta by means of insertion of synthetic prosthetic grafts (ie, historical series from the 1980s) provide arguments for the relevance of the presently described hemodynamic consequences of prosthetic aortic bypass. Despite the excellent early clinical results, an increased number of patients showed aneurysm formation at the repair site, and the aneurysms that develop after aortic repair are true aneurysms, as opposed to false aneurysms occurring at the suture line. ${ }^{25-27}$ Aortic wall weakness, compliance mismatch between graft and native wall, and abnormal hemodynamics as flow acceleration and turbulence patterns have been advocated as underlying physiopathologic mechanisms..$^{21,28,29}$ The diastolic changes we report here, coupled with increasing presystolic emergence of $\mathrm{Ze}$ peaks in the immediate upstream and downstream vicinity of the stiff graft, provide realistic explanations for transient flow accumulation, resulting in the presence of a presystolic transitory blood vortex in both areas where aneurysm and dilation occurred. ${ }^{28,29}$ These are supported by recent findings obtained by investigating changes in geometry, and strain of 3-dimensional reconstructed synthetic patch repair of aortic coarctation substantially increases the wall stress immediately adjacent to the aorta, ${ }^{26}$ which is to be accounted for by the hemodynamic changes we observed in the TA.

Finally, the cardiac consequences of the present study remain speculative in the midterm and long-term, although the newly alleviated hemodynamics in the AA and arch are likely to release a chronic compensatory cardiac response in the long term. Such an assumption might answer the unidentified mechanisms underlying the unpredictable pattern of the cardiac consequences of left ventricular remodeling in patients after successful repair of coarctation of the aorta. ${ }^{30}$ The mechanisms of increased relative wall thickness and reduced peak and end-systolic wall stresses are still unknown but are potentially accounted for by the changes in hemodynamics we report here.

\section{Conclusions}

The originality of our work consisted in a new approach for analysis of $\mathrm{P}-\mathrm{Q}$ waves, $\mathrm{P}-\mathrm{Q}$ loops, and $\overline{\mathrm{Ze}}$ profile in the thoracic aorta along a mean cardiac cycle to demonstrate that the natural hemodynamics provided assistance to the flow with an unexpected diastolic $\overline{\mathrm{Ze}}$ peak facilitating tissue perfusion. Our approach highlights that, upstream of the graft, the surgical procedure impaired the diastolic assistance effect to blood flow to the coronary and supra-aortic trunks. On a long-term basis and with regard to the absence of cardiac compensatory mechanisms, it remains to established whether such modifications might lead to cardiac and arterial deterioration and further organ dysfunction. Further studies should involve orthotopic grafting, should compare various types of substitutes, including aortic stent grafts, or both. Alternate type of grafts should be designed along with better design of anastomotic junctions and should be submitted to in vivo experimental quality control assessment using the presently described hemodynamic characteristics before clinical use.

\section{References}

1. Kelly RP, Tunin R, Kass DA. Effect of reduced compliance on cardiac efficiency and contractile function of in situ canine left ventricle. Circ Res. 1992;71:490-502.

2. Kass DA, Saeki A, Tunin RS, Recchia FA. Adverse influence of systemic vascular stiffening on cardiac dysfunction and adaptation to acute coronary occlusion. Circulation. 1996;93:1533-41.

3. Morita S, Kuboyama I, Asou T, Tokunaga K, Nose Y, Nakamura M, et al. The effect of extraanatomic bypass on aortic input impedance studied in open chest dogs. Should the vascular prosthesis be compliant to unload the left ventricle? J Thorac Cardiovasc Surg. 1991;102: $774-83$.

4. Dujardin JP, Stone DN, Paul LT, Pieper HP. Response of systemic arterial input impedance to volume expansion and hemorrhage. Am J Physiol. 1980;238:H902-8.

5. Urschel CW, Covell JW, Sonnenblick EH, Ross J Jr, Braunwald E. Effects of decreased aortic compliance on performance of the left ventricle. Am J Physiol. 1968;214:298-304.

6. Appleyard RF, Sauvage LR. Haemodynamic consequences of arterial replacement with a synthetic graft. Cardiovasc Res. 1986;20:26-35.

7. Bauernschmitt R, Schulz S, Schwarzhaupt A, Kiencke U, Vahl CF, Lange R, et al. Simulation of arterial hemodynamics after partial prosthetic replacement of the aorta. Ann Thorac Surg. 1999;67:676-82.

8. Segers P, Stergiopulos N, Schreuder JJ, Westerhof BE, Westerhof N. Left ventricular wall stress normalization in chronic pressure-overloaded heart: a mathematical model study. Am J Physiol. 2000;279:H1120-7.

9. Eaton GM, Cody RJ, Binkley PF. Increased aortic impedance precedes peripheral vasoconstriction at the early stage of ventricular failure in the paced canine model. Circulation. 1993;88:2714-21.

10. Cooper G IV. Basic determinants of myocardial hypertrophy: a review of molecular mechanisms. Annu Rev Med. 1997;48:13-23.

11. Wong K, Boheler KR, Petrou M, Yacoub MH. Pharmacological modulation of pressure-overload cardiac hypertrophy_changes in ventricular function, extracellular matrix, and gene expression. Circulation. 1997; $96: 2239-46$.

12. Oe M, Asou T, Morita S, Yasui H, Tokunaga K. Protamine-induced hypotension in heart operations: application of the concept of ventricular-arterial coupling. J Thorac Cardiovasc Surg. 1996;112:462-71. 
13. Nelson GS, Berger RD, Fetics BJ, Talbot M, Hare JM, Kass DA, et al. Left ventricular or biventricular pacing improves cardiac function at diminished energy cost in patients with dilated cardiomyopathy and left bundle-branch block. Circulation. 2000;102:3053-9.

14. Grossi EA, Kanchuger MS, Schwartz DS, McLoughlin DE, LeBoutillier M III, Ribakove GH, et al. Effect of cannula length on aortic arch flow: protection of the atheromatous aortic arch. Ann Thorac Surg. 1995;59:710-2.

15. Grossi EA. Fourier analysis of the intra-aortic balloon pump. J Thorac Cardiovasc Surg. 1999;118:568.

16. Quick CM, Young WL, Noordergraaf A. Infinite number of solutions to the hemodynamic inverse problem. Am J Physiol. 2001;280: H1472-9.

17. Kelly RP, Ting CT, Yang TM, Liu CP, Maughan WL, Chang MS, et al. Effective arterial elastance as index of arterial vascular load in humans. Circulation. 1992;86:513-21.

18. Rolland PH, Charifi AB, Verrier C, Bodard H, Friggi A, Piquet P, et al. Hemodynamics and wall mechanics after stent placement in swine iliac arteries: comparative results from six stent designs. Radiology. 1999;213:229-46.

19. Mekkaoui C, Friggi A, Rolland PH, Bodard H, Piquet P, Bartoli JM, et al. Simultaneous measurements of arterial diameter and blood pressure to determine the arterial compliance, wall mechanics and stresses in vivo. Eur J Vasc Endovasc Surg. 2001;21:208-13.

20. Rolland PH, Friggi A, Barlatier A, Piquet P, Latrille V, Faye MM, et al. hyperhomocysteinemia-induced vascular damage in the minipig. Captopril-hydrochlorothiazide combination prevents elastic alterations. Circulation. 1995;91:1161-74.

21. Berry JL, Moore JE, Newman VS, Routh WD. In vitro flow visualisation in stented arterial segments. $J$ Vasc Invest. 1997;3:3-8.

22. Hagl C, Ergin MA, Galla JD, Lansman SL, Mccullough JN, Spielvogel D, et al. Neurologic outcome after ascending aorta-aortic arch operations: effect of brain protection technique in high-risk patients. J Thorac Cardiovasc Surg. 2001;121:1107-21.

23. Ehrlich MR, Hagl C, Mccullough JN, Zhang N, Shiang H, Bodian C, et al. Retrograde cerebral perfusion provides negligible flow through brain capillaries in the pig. J Thorac Cardiovasc Surg. 2001;122: 331-8.

24. Cooley DA, Golino A, Frazier OH. Single-clamp technique for aneurysms of the descending thoracic-aorta: report of 132 consecutive cases. Eur J Cardiothorac Surg. 2000;18:162-7.

25. Hehrlein FW, Mulch J, Rautenburg HW, Schlepper M, Scheld HH. Incidence and pathogenesis of late aneurysms after patch graft aortoplasty for coarctation. J Thorac Cardiovasc Surg. 1986;92:226-30.

26. Smaill BH, McGiffin DC, Legrice IJ, Young AA, Hunter PJ, Galbraith AJ. The effect of synthetic patch repair of coarctation on regional deformation of the aortic wall. J Thorac Cardiovasc Surg. 2000;120: 1053-63.

27. Heikkinen L, Sariola H, Salo J, Ala-Kulju K. Morphological and histopathological aspects of aneurysms after patch aortoplasty for coarctation. Ann Thorac Surg. 1990;50:946-8.

28. Bogaert J, Dymarkowski S, Budts W, Gewillig M, Daenen W. Graft dilation after redo surgery for aneurysm formation following patch angioplasty for aortic coarctation. Eur J Cardiothorac Surg. 2001;19: 274-8.

29. Kanter KR, Erez E, Williams WH, Tam VK. Extra-anatomic aortic bypass via sternotomy for complex aortic arch stenosis in children. J Thorac Cardiovasc Surg. 2000;120:885-90.

30. Pacileo G, Pisacane C, Russo MG, Crepaz R, Sarubbi B, Tagliamonte $\mathrm{E}$, et al. Left ventricular remodeling and mechanics after successful repair of aortic coarctation. Am J Cardiol. 2001;87:748-52.

\section{Appendix 1}

The measured waves underwent the segmentation process into consecutive segments separated by 2 opposite extreme points defined as the location of the minimum and maximum, which were identified by using the following algorithm. Each maximum was determined in the wave as $\mathrm{P}_{\operatorname{maxi}}=\left(\mathrm{t}_{1}, \mathrm{y}_{1}\right)$, with $\mathrm{y}_{1}$ obeying the condition $\mathrm{y}_{1-1}<\mathrm{y}_{\mathrm{i}}>\mathrm{y}_{\mathrm{i}+1}$, and each minimum as $\mathrm{P}_{\text {mini }}=\left(\mathrm{t}_{\mathrm{i}}, \mathrm{y}_{\mathrm{i}}\right)$,

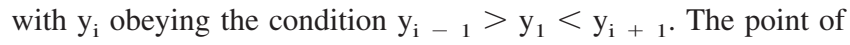
origin, $\mathrm{p} 0=\left(\mathrm{t}_{0}, \mathrm{y}_{0}\right)$, initially was found to be a maximum or a minimum entity when $\mathrm{y}_{0}>\mathrm{y}_{0+1}$ or $\mathrm{y}_{0}<\mathrm{y}_{0+1}$, respectively. As a result of segmentation of the original pulse wave, the $J$ segment had the extreme coordinates: $\left.J_{\max }\right|_{y_{j M}} ^{t_{j M}},\left.J_{\min }\right|_{y_{j m}} ^{t_{j m}}$.

\section{Appendix 2}

The basic mathematic model considered that the curve was the second derivative of a sigmoidal function and extracted the elementary segment between the minimum and maximum (shown in Figure 2). It follows that $\mathrm{f}(\mathrm{t})$ is the sigmoidal function and $\phi(t)$ is the second derivative. Therefore:

$f(t)=\frac{1}{2}\left(\frac{1-\exp (t)}{1-\exp (t)}\right) \stackrel{\text { second derivative }}{\longrightarrow} f^{\prime \prime}(t)=\phi(t)$

$$
=\frac{\exp (3 t)-\exp (t)}{(\exp (t)+1)^{4}}
$$

The function $\phi(t)$ is the result of 2 reverse and shifted waves:

$$
g(t)=\frac{\exp (3 t)}{(\exp (t)+1)^{4}} \text { and } h(t)=-\frac{\exp (t)}{(\exp (t)+1)^{4}}
$$

The use of a door function, $\Pi$, extracts useful part of the curve only:

$\Pi(t)=\left\{\begin{array}{ll}1 & t_{1} \leq t \leq t_{2} \\ 0 & \text { elsewhere }\end{array}\right.$ where $\phi^{\prime}\left(t_{1}\right)=0$ and $\phi^{\prime}\left(t_{2}\right)=0$

The analytic expression of the elementary segment is as follows:

$$
\begin{aligned}
\Psi(t)=\{g(t)+h(t)\} \times \Pi(t)=\{g(t)+ & h(t)\}_{n} \\
& =\left\{\frac{\exp (3 t)-\exp (t)}{(\exp (t)+1)^{4}}\right\}_{\Pi}
\end{aligned}
$$

The $\mathrm{J}$ segment, obtained as described in Appendix 1, was fitted with the model as follows. From the extreme coordinates of the J segment $\left.J_{\max }\right|_{y_{j M} M} ^{t_{j M}},\left.J_{\min }\right|_{y_{j m}} ^{t_{j m}}$. the model segment was scaled so that $\Psi_{\mathrm{j}}\left(\mathrm{t}_{\mathrm{jM}}\right)=\mathrm{y}_{\mathrm{jM}} ; \Psi\left(\mathrm{y}_{\mathrm{jm}}\right)=\mathrm{y}_{\mathrm{jm}}$ to yield the subsequent function that fit each waveform segment:

$\Psi_{j}(t)=\eta_{j}\left\{\frac{\left[\exp \left(\frac{3\left(t-\delta_{j}\right)}{\sigma_{j}}+\alpha_{j}\right)-\exp \left(\frac{t-\delta_{j}}{\sigma_{j}}+\alpha_{j}\right)\right]}{\left[\exp \left(\frac{t-\delta_{j}}{\sigma_{j}}\right)+1\right]^{4}}\right\}_{n}+\vartheta_{j}$

Scaling the curve required the introduction of the following parameters. The definition domain of $\mathrm{J}$ segment identified $\mathrm{A}_{\mathrm{j}}$ along the ordinate scale with $A_{j}=\left|y_{j M}-y_{j m}\right|$ and $\mathrm{B}_{\mathrm{j}}$ along the abscissa scale with $B_{j}=\left|t_{j M}-t_{j m}\right|$. The segment of curve was scaled with $\alpha_{\mathrm{j}}$ and $\sigma_{\mathrm{j}}$ as 2 values determined, by using an empiric method, to be $\alpha_{\mathrm{j}}=\ln \left(5,2 \mathrm{~A}_{\mathrm{j}}\right)$ and $\sigma_{j}=\frac{B_{j}}{3,3}$. Offsets in the function were accounted for by introducing the parameter $\delta_{j}=\frac{t_{j M}+t_{j m}}{2}$ in the horizontal offset and $\vartheta_{j}=\frac{\Gamma_{j}}{\left|\Gamma_{j}\right|} \Gamma_{j}$ where $\Gamma_{\mathrm{j}}=\mathrm{y}_{\mathrm{jm}}-\mathrm{y}_{\mathrm{m}}$ in the 
vertical offset for each waveform segment, with $M_{\max }\left|t_{y_{M}}, M_{\min }\right|_{y_{m}}^{t_{m}}$ as the extreme coordinates of the model segment. The parameter $\eta_{j}$ accounted for the increasing or decreasing nature of the waveform segment, with $\eta_{j}=\frac{\Lambda_{j}}{\left|\Lambda_{j}\right|}$ where $\Lambda_{j}=\frac{t_{j M}-t_{j m}}{y_{j M}-y_{j m}}$.

\section{Appendix 3}

The measured wave was reconstructed through a series of initial fits and error functions (Figure 3), with successive models being obtained by treating the measured wave and recurrent errors with equation 1. The first model m0: $\xi_{0}(t)=\sum_{k=1}^{l} \Psi_{k}(t)$, although a reasonable approximation of the measured curve, still contained significant error (error 0). Error 0 was then fit with equation 1, yielding $\mathrm{m} 1: \xi_{1}(t)=\sum_{k=1}^{m} \Psi_{k}(t)$ and error 1 . This error was subsequently fit with equation 1, yielding $\mathrm{m} 2: \xi_{2}(t)=\sum_{k=1}^{n} \Psi_{k}(t)$, where 1, $\mathrm{m}$, and $\mathrm{n}$ were, respectively, the number of segments that make up $\mathrm{m} 0, \mathrm{~m} 1$, and $\mathrm{m} 2$. The 3 resulting models were summed to obtain the final synthesized waveform as follows:

$$
\Omega(t)=\sum_{k=0}^{2} \xi_{k}(t)
$$

The accuracy (physics, geometrics, and statistics) was checked by using a quadratic error normalized to the original pulse wave, according to the following:

$$
\epsilon=\frac{\int_{0}^{T}(S(t)-\Omega(t))^{2} d t}{\int_{0}^{T}(S(t))^{2} d t}
$$

where the discrete counterpart is

$$
\epsilon=\frac{\sum_{i=1}^{256}\left(S_{i}-\Omega_{i}\right)^{2}}{\sum_{i=1}^{256}\left(S_{i}\right)^{2}} \equiv \frac{\|S-\Omega\|^{2}}{\|S\|^{2}}
$$

where $\mathrm{S}$ was the measured wave, $\mathrm{T}$ was the mean cardiac cycle period value, and $t$ was the time variable. In each case the error was found to be on the order of $10^{-7}$.

\section{Appendix 4}

Mean hemodynamics of pressure and flow waves were determined as the systolic (maximum), diastolic (minimum), pulse $(\Delta=\mid \max$ $-\min \mid$ ) and mean values, as computerized from their respective $\Omega_{\mathrm{p}}(\mathrm{t})$ and $\Omega_{\mathrm{Q}}(\mathrm{t})$ functions and expressed as millimeters of mercury and milliliters per minute, respectively. The algebraic mean pressure $(\overline{\mathrm{P}})$ and flow $(\overline{\mathrm{Q}})$ values are calculated as $\bar{P}=\frac{1}{T} \int_{0}^{T} \Omega_{p}(t) d t$ and $\bar{Q}=\frac{1}{T} \int_{0}^{T} \Omega_{Q}(t) d t$ respectively, with T:mean cardiac cycle period value.

Parametric equations of hysteresis loops for P-Q relationships (Figure 3) were defined as follows:

$\left\{\begin{array}{l}X=\Omega_{p}(t), \\ Y=\Omega_{Q}(t) .\end{array} \quad 0 \leq t \leq T\right.$.

Peripheral resistance $\left(\mathrm{PR} ; \mathrm{mm} \mathrm{Hg} \cdot \mathrm{mL}^{-1} \cdot \mathrm{min}^{-1}\right)$ and mean entry impedance $\left(\overline{Z e}, \mathrm{~mm} \mathrm{Hg} \cdot \mathrm{mL}^{-1} \cdot \mathrm{min}^{-1}\right)$ were calculated as $P R$ $=\frac{\bar{P}}{\bar{Q}}$, and $\overline{Z e}=\frac{\Delta P}{\Delta Q}\left(\Delta \mathrm{P}=\mathrm{P}_{\max }-\mathrm{P}_{\min }, \Delta=\mathrm{Q}_{\max }-\mathrm{Q}_{\min }\right)$, respectively.

The instantaneous $\mathrm{Z} e\left(\right.$ in $\mathrm{kN} \cdot \mathrm{s} \cdot \mathrm{m}^{-5}$ ) during the cardiac cycle is the ratio of the function of the pressure and flow:

$Z e=\frac{\Omega_{p}(t)}{\Omega_{Q}(t)}=\frac{\sum_{k=0}^{2} \xi_{p k}}{\sum_{k=0}^{2} \xi_{Q_{k}}}$ 